\title{
Comparison of the tuberculin test, histopathological examination, and bacterial culture for the diagnosis of tuberculosis (Mycobacterium bovis) in buffaloes (Bubalus bubalis) in Brazil
}

\author{
Tatiane Teles Albernaz ${ }^{1}$ Carlos Magno Chaves Oliveira ${ }^{1}$ Danillo Henrique da Silva Lima ${ }^{1}$. \\ Natália da Silva e Silva ${ }^{1}$ Douglas Pinheiro Cardoso ${ }^{1}$ - Cinthia Távora Albuquerque Lopes ${ }^{1}$. \\ Marilene de Farias Brito $^{2}$. Jenevaldo Barbosa da Silva ${ }^{3}$ - Felipe Masiero Salvarani ${ }^{1}$. \\ Rômulo Cerqueira Leite ${ }^{4}$. José Diomedes Barbosa ${ }^{1}$
}

Received: 5 September 2014 / Accepted: 27 April 2015 / Published online: 10 May 2015

(C) Springer Science+Business Media Dordrecht 2015

\begin{abstract}
Tuberculosis is a disease with a great zoonotic potential. It is considered a major obstacle to cattle production and is responsible for severe losses in several production systems. A comparative cervical test (CCT) was performed in 1140 buffaloes from different mesoregions of the state of Pará, Brazil, with the aim of comparing the sensitivity and specificity of CCT with histopathological examination and bacterial culture. Of the animals tested using CCT, $4.65 \%$ (53/1140) were positive, $2.98 \%$ (34/1140) were inconclusive, and $92.36 \%(1053 / 1140)$ were negative. Among the 168 sacrificed animals, 33 were positive, 18 were inconclusive, and 117 were negative by CCT, and samples from the sacrificed animals were collected for histopathological examination and bacterial culture. A qualitative evaluation of the tuberculin test was performed by comparing the test results with the histopathological and bacteriological results. The
\end{abstract}

José Diomedes Barbosa

diomedes@ufpa.br

Jenevaldo Barbosa da Silva

jenevaldo@hotmail.com

1 Instituto de Medicina Veterinária, Universidade Federal do Pará, Rodovia BR 316 Km 61, Bairro Saudade, 68740-970 Castanhal, PA, Brazil

2 Departamento de Epidemiologia e Saúde Pública, Instituto de Veterinária, UFRRJ, Seropédica, RJ, Brazil

3 Departamento de Patologia Veterinária, Faculdade de Ciências Agrárias e Veterinárias FCAV-UNESP, Laboratório de Imunoparasitologia, Via de Acesso Prof. Paulo Donato Castellane s/n, 14884-900 Jaboticabal, SP, Brazil

4 Laboratório de Retroviroses, Departamento de Medicina Veterinária Preventiva, Escola de Veterinária, Universidade Federal de Minas Gerais, Belo Horizonte, MG, Brazil latter two tests yielded a prevalence of $4.16 \%$, a sensitivity of $71.43 \%$, and a specificity of $82.61 \%$. Based on these results, we concluded that CCT yielded satisfactory results and can be applied in diagnostic studies in buffaloes. The prevalence rate obtained using three distinct diagnostic methods suggests that Mycobacterium bovis was present in a few animals in the population evaluated.

Keywords Mycobacterium bovis · Buffalo · Sensibility · Specificity $\cdot$ Zoonotic

\section{Introduction}

Brazil has a large buffalo herd comprising approximately 1, 200,000 animals. The state of Pará has the greatest herd in the country, with approximately 500,000 animals (IBGE 2013). In this state, farmers have shown growing interest in buffalo farming for the production of meat, milk, and milk derivatives. Buffalo-derived, high-quality products include tender and low-cholesterol meat and high-fat milk (Láu 1999). However, health priorities for the buffalo herds in northern Brazil have not been established to date.

Meat and milk are essential products for domestic consumption and export in South America; therefore, eliminating the diseases that limit the trade of animal and animal products is a priority for this region (Zumarraga et al. 2005). Considering their robustness, it is believed that buffaloes are resistant to various diseases that affect cattle. However, it has been reported that they are susceptible to several infectious agents that affect cattle, including Mycobacterium bovis, the etiologic agent of tuberculosis (Barbosa et al. 2014). Tuberculosis is a zoonotic disease of worldwide distribution 
that is responsible for severe economic losses to the production chain and is of great economic and social impact in Brazilian agribusiness. In Brazil, the control and eradication of tuberculosis are based on the guidelines established by the National Program for Control and Eradication of Brucellosis and Tuberculosis (NPCEBT), which is regulated by the Ministry of Agriculture, Livestock, and Food Supply (MAPA 2006). However, this program was specifically implemented for cattle.

Several factors have limited the effective diagnosis of tuberculosis in the buffalo population, including a lack of data on disease prevalence and incidence in Brazilian herds (Barbosa et al. 2014). Furthermore, the role of atypical mycobacteria in the epidemiology of tuberculosis in buffaloes remains understudied. Another limitation is related to the lack of specific parameters for allergic cutaneous diagnostic tests in buffaloes; these parameters are necessary for the development of a scoring system for interpreting allergic responses to tuberculin. For this purpose, the scoring criteria established for cattle will be used as a standard, as recommended by NPCEBT (MAPA 2006), until a specific scoring system is available for the buffalo population.

Bovine tuberculosis can be diagnosed using direct and indirect methods, including the detection and identification of the etiologic agent and evaluation of the host immune response to infection (Michel and Simões 2009). The tuberculin, histopathological, and bacteriological tests are most commonly used for the diagnosis of tuberculosis in bovine and buffalo populations in Brazil. However, the nonspecificity of clinical signs, the difficulty in isolating M. bovis from live animals, and low antibody titers during the initial phase of infection limit the effectiveness of clinical, bacteriological, and serological diagnostic tests (Álvarez et al. 2014). Therefore, with a view towards establishing safe criteria for the diagnosis of tuberculosis in buffaloes, the present study aimed to make a comparative assessment of the tuberculin, histopathological, and bacteriological tests.

\section{Materials and methods}

The study was conducted on 11 rural properties located in the state of Pará: the towns of Ipixuna (1), Nova Timboteua (1) and Castanhal (1) in the mesoregion of northeastern Pará; Soure (1) and Cachoeira-do-Arari (2) in the mesoregion of Marajó Island; and Oriximiná (5) in the Lower Amazon mesoregion in Pará.

A total of 1140 young and adult buffaloes of both sexes were examined, belonging to the Murrah, Mediterrâneo, and Jafarabadi breeds, as well as mixed breeds, for the production of meat and milk. These animals were reared using an extensive farming system together with cattle and horses. All buffaloes were vaccinated against foot-and-mouth disease (FMD) and brucellosis and were wormed regularly but did not receive mineral supplementation.

For field diagnosis of tuberculosis, CCT was performed following NPCEBT recommendations (MAPA 2006). The tuberculins used were purified protein derivatives (PPDs) of bovine and avian origin at concentrations of $5000 \mathrm{DI}(1 \mathrm{mg} /$ $\mathrm{mL})$ and $2500 \mathrm{DI}(0.5 \mathrm{mg} / \mathrm{mL})$ per dose, respectively. This material was provided by the National Agricultural Laboratory of Minas Gerais (Laboratório Nacional Agropecuário de Minas Gerais-LANAGRO/MG) located in the city of Pedro Leopoldo, Minas Gerais.

Seven days after performance of the tuberculin test in 1140 animals, 168 animals were sacrificed. Buffaloes from the mesoregions of Northeast Pará and Marajó Island were sacrificed at the slaughterhouse of the Cooperative Society and Livestock Industry of Pará located in the city of Belém, Pará, whereas animals from the Lower Amazon mesoregion were sacrificed at the slaughterhouse located in the city of Manaus, Amazonas. Individual retropharyngeal, mediastinal, and mesenteric lymph node samples were collected at the time the animals were sacrificed for histopathological examination and bacterial culture and for examination of lesions that were suggestive of tuberculosis.

For histopathological examination, 168 samples were fixed in $10 \%$ buffered formalin solution. After fixation, the material was embedded in paraffin, cut with a microtome, and stained with hematoxylin and eosin and Ziehl-Neelsen stain in the Division of Pathological Anatomy at the Federal Rural University of Rio de Janeiro.

For bacterial culture, 168 samples were transferred to sterile tubes, placed in insulated containers with dry ice, and sent to LANAGRO/MG for processing. Samples of connective and adipose tissue were removed with a scalpel and cut into 2-3-mm-thick sections. Sterilization was performed with $6 \%$ sulfuric acid $\left(\mathrm{H}_{2} \mathrm{SO}_{4}\right)$ at a ratio of one part sample to six parts $\mathrm{H}_{2} \mathrm{SO}_{4}$ solution for $30 \mathrm{~min}$ followed by centrifugation at $500 \mathrm{~g}$ for $15 \mathrm{~min}$. The sediment was washed twice with phosphate buffered saline (PBS) and transferred to test tubes containing Stonebrink and Lowenstein-Jensen selective media and incubated at $37^{\circ} \mathrm{C}$ for up to 8 weeks.

Sensitivity and specificity were calculated according to Henken et al. (1997) using WinEpiscope software version 2.0 (Blas Ortega, Frankena, Noordhuizen, Thrusfiled; Veterinary School of Zaragoza, Wagening University, University of Edinburgh).

\section{Results}

\section{Tuberculin test}

Of 1140 buffaloes tested using the CCT method, $4.65 \%$ (53/ 1140 ) were positive, $2.98 \%$ (34/1140) were inconclusive, and 
$92.36 \%(1053 / 1140)$ were negative. Among the animals tested, 168 were sacrificed, and of these, $62.26 \%(33 / 53)$ were positive, $52.94 \%(18 / 34)$ were inconclusive, and $11.11 \%$ $(117 / 1053)$ were negative.

Of the 53 positive animals, 33 were monitored until the time of sacrifice. Table 1 shows the number of sacrificed animals with positive, inconclusive, and negative reactions using CCT for tuberculosis and their regions of origin.

\section{Histopathological examination}

Macroscopic examination of the lymph node samples indicated the presence of lesions suggestive of tuberculosis, characterized by the presence of nodules of firm consistency and color ranging from white or gray to yellow. The sections had a sandy appearance. The lesion core was caseous and yellowish, generally dry and solid, and surrounded by a whitish capsule (Fig. 1).

This examination also indicated that, of the 168 animals examined, 7 had macroscopic lesions suggestive of tuberculosis. Five of the seven buffaloes with macroscopic lesions also exhibited histopathological lesions suggestive of tuberculosis in their mediastinal and mesenteric lymph nodes. The lesions were histologically classified as tuberculoid granulomas of varying sizes with central caseous necrosis and often with foci of mineralization. Furthermore, these lesions were accompanied by marked macrophage reactions with several epithelioid cells, lymphocytes, plasmocytes, neutrophils, fibroblasts, and collagen. At the boundary between the necrotic area and the inflammatory reaction site, some Langhans giant cells were observed. Ziehl-Neelsen staining revealed the presence of several alcohol acid-resistant bacilli near the necrotic area, which were phagocytosed by macrophages and giant cells (Figs. 2, 3, and 4).

A qualitative analysis of the comparison between the allergic-cutaneous and histopathological test results indicated that $15.15 \%(05 / 33)$ of the animals were true positives, $84.84 \%$ (28/33) were false positives, $98.52 \%(133 / 135)$ were true negatives, and $1.48 \%(02 / 135)$ were false negatives (Table 2). An analysis of samples from the sacrificed animals indicated a prevalence of $4.16 \%$, sensitivity of $71.43 \%$, specificity of $82.61 \%$, positive predictive value of $15.15 \%$, negative predictive value of $98.52 \%$, and overall coefficient of $82.14 \%$ (Fig. 5).

\section{Bacterial culture}

Macroscopic analysis of lymph nodes indicated that, of the 168 animals examined, 7 had macroscopic lesions suggestive of tuberculosis.

A qualitative analysis of the comparison between the tuberculin test and bacterial culture revealed that $15.15 \%(5 / 33)$ animals were true positives, $84.84 \%$ (28/33) were false positives, $98.52 \%(133 / 135)$ were true negatives, and $1.48 \%$ (2/135) were false negatives (Table 3$)$. The prevalence rate was $4.16 \%$, sensitivity was $71.43 \%$, specificity was $82.61 \%$, positive predictive value was $15.15 \%$, negative predictive value was $98.52 \%$, and the overall coefficient was $82.14 \%$ (Fig. 6).

\section{Discussion}

The first studies on the prevalence of $M$. bovis in buffaloes were conducted in 1986 in Egypt. Since then, studies have reported an increased prevalence of bovine tuberculosis in several parts of the world (Phillips et al. 2003; Cleaveland et al. 2007; Tschopp et al. 2009; Javed et al. 2010). By CCT, the prevalence rate of tuberculosis in buffaloes was $4.65 \%$ (53/1140). In Brazil, this result was lower than that obtained in previous studies on buffaloes conducted by Mello et al. (1965) (15.2\%) and Portugal et al. (1971) (6.04 \%) in the state of São Paulo, Mota et al. (2002) (20.4\%) in the state Amazonas, and Barbosa et al. (2014) (7.2 \%) in Pará. However, this prevalence was higher than that reported by Barbosa et al. (2014) (3.5\%) in Marajó Island, Pará. The low prevalence rate found herein may be associated with the type of extensive animal farming adopted, which may have limited physical contact between infected and susceptible animals, as previously reported by Barbosa et al. (2014) in Marajó Island, where highly extensive farming was used.
Table 1 Number of sacrificed buffaloes (Bubalus bubalis) with positive, inconclusive, and negative reactions using the comparative cervical test for tuberculosis in the north region of Brazil

\begin{tabular}{lllll}
\hline Region & Positive & Inconclusive & Negative & $\begin{array}{l}\text { Total number of } \\
\text { animals sacrificed }\end{array}$ \\
\hline Cachoeira do Arari & 0 & 2 & 6 & 8 \\
Ipixuna & 3 & 1 & 16 & 20 \\
Nova Timboteua & 2 & 5 & 30 & 37 \\
Oriximiná & 23 & 7 & 36 & 66 \\
Soure & 5 & 3 & 29 & 37 \\
Total & 33 & 18 & 117 & 168 \\
\hline
\end{tabular}




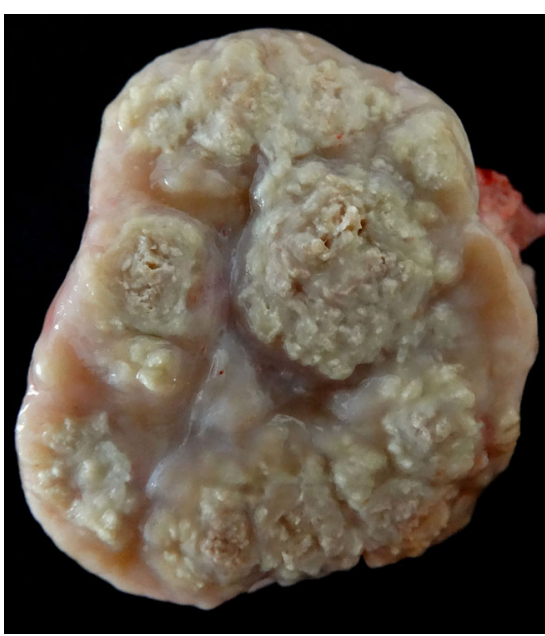

Fig. 1 Tuberculosis in a buffalo lymph node. Cross-section of the lymph node, with yellowish-white, multifocal to coalescing, irregular areas with distinct zones of calcification. The large area affected by tuberculous lesions is clearly delimited by the lymphatic tissue

According to Seva et al. (2014), non-specific reactions may greatly interfere with interpreting tuberculin test results in areas with a low prevalence of tuberculosis, which can conceal disease outbreaks or misdiagnose healthy animals when test results are not properly interpreted. These authors attributed these reactions to Mycobacterium avium, Mycobacterium avium subsp. paratuberculosis, and other saprophytic or facultative pathogenic mycobacteria. The variation in disease prevalence in the locations studied may be a result of the farming system adopted, which in some cases can favor disease development and infection transmission, but may also be associated with specific environmental factors. Accordingly, Barbosa et al. (2014) reported a large variation in the prevalence of tuberculosis between regions for water buffalo in Pará, Brazil.

The results of the present study demonstrated that the comparative intradermal tuberculin test yielded a high rate of false positive and true negative reactions. The inability to isolate

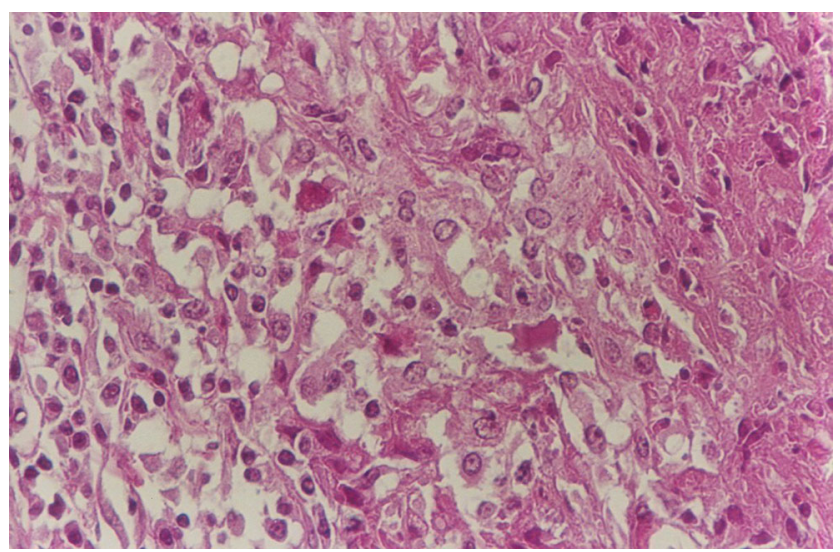

Fig. 2 Tuberculosis in a buffalo lymph node. Granulomatous inflammation with epithelioid cells and lymphocytes (left) and caseous necrosis (upper right corner). $\mathrm{HE}, \times 40 \mathrm{obj}$

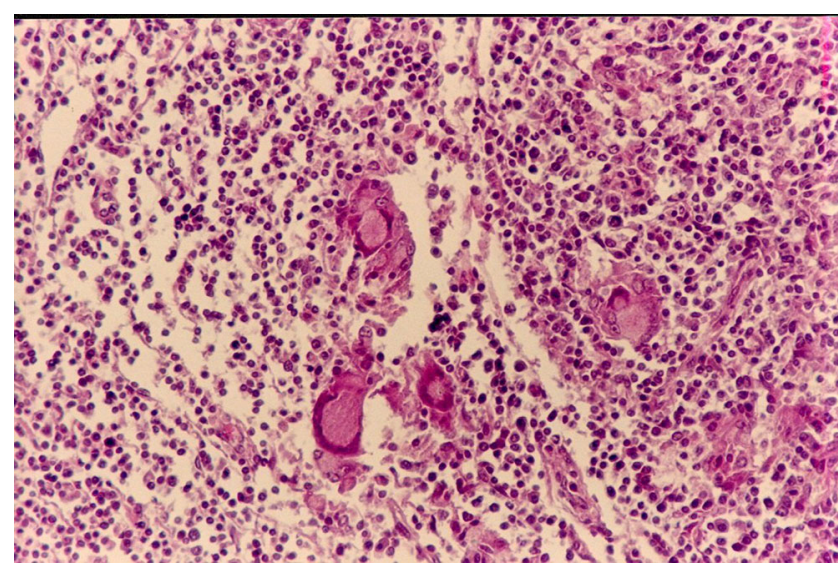

Fig. 3 Histological section of a buffalo mediastinal lymph node showing a tuberculous granuloma. Neutrophils are abundant in the center of the granuloma and are surrounded by macrophages, multinucleated Langerhans giant cells and lymphocytes. HE, $\times 25 \mathrm{obj}$

mycobacteria in $84.84 \%$ of the samples from animals that reacted to tuberculin may be associated with a decreased load of $M$. bovis in lymph nodes at the time of sampling or with difficulties inherent to the method used for isolating these etiological agents, which were potentially present in many samples owing to the high rate of contamination during sample collection.

The low sensitivity observed in the bacteriological test has been previously reported in buffaloes by Monaghan et al. (1994) and in cattle by Pinto et al. (2002). According to these authors, the absence of mycobacteria in macroscopic lesions suggestive of tuberculosis can be explained by (1) failure of the isolation method due to inactivation of mycobacteria during sterilization or due to culturing difficulties, (2) inactivation of mycobacteria triggered by the host immune system, and (3) injuries caused by other animals. However, after isolation and identification of M. bovis, bacterial culture is highly reliable, can achieve a specificity of $100 \%$, and is therefore regarded as the gold standard for the diagnosis of tuberculosis. For this reason, samples from animals whose lesions have not been

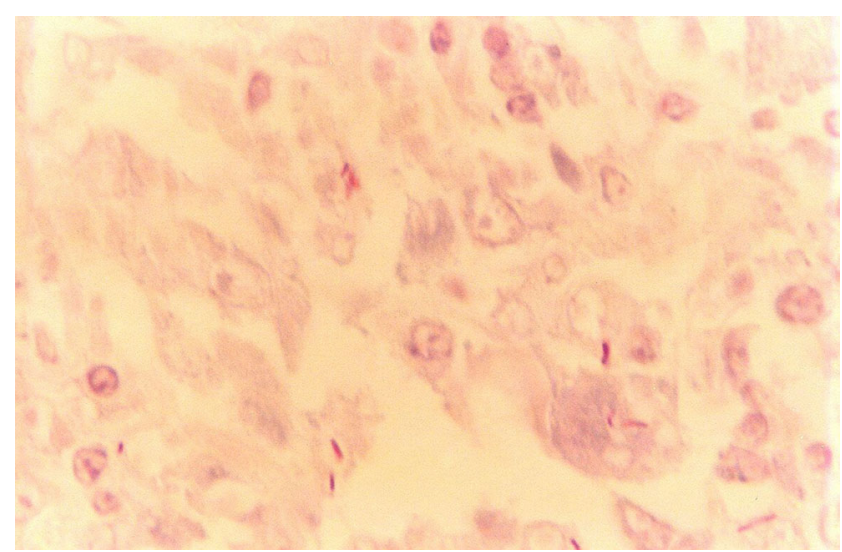

Fig. 4 Tuberculosis in a buffalo lymph node. Granulomatous inflammation with epithelioid cells and bacilli (Mycobacterium sp.) phagocytosed by macrophages (arrows). Ziehl-Neelsen, $\times 100 \mathrm{obj}$ 
Table 2 Qualitative analysis of the comparison between the tuberculin and histopathological tests for tuberculosis diagnosis in buffaloes (Bubalus bubalis) from the north region of Brazil

\begin{tabular}{llll}
\hline Tuberculin test & \multicolumn{2}{l}{ Histopathological test } & Total \\
\cline { 2 - 3 } & Positive & Negative & \\
\hline Positive & $5(15.15 \%)(\mathrm{TP})$ & $28(84.84 \%)(\mathrm{FP})$ & 33 \\
Negative & $2(1.48 \%)(\mathrm{FN})$ & $133(98.52 \%)(\mathrm{TN})$ & 135 \\
Total & 7 & 161 & 168 \\
\hline
\end{tabular}

$T P$ true positive, $F P$ false positive, $T N$ true negative, $F N$ false negative

fully characterized should always be confirmed by bacterial culture.

The low sensitivity of bacterial culture in the present study may be due to the sterilization techniques used during sample processing, because all lesions must be exposed for visual examination at the time of animal sacrifice during the sterilization step, which may have contributed to bacterial inactivation and consequently to the low isolation rate. This problem has been reported frequently during sample collection at the time of sacrifice. Therefore, although bacterial culture is the gold standard, it should not be used as an isolated test for the diagnosis of tuberculosis in buffaloes.

According to Wood et al. (1991) and Monaghan et al. (1994), intradermal tests are not very specific and the occurrence of false positives, which can result in unnecessary animal sacrifice, often jeopardizes the credibility of the entire control program. Therefore, a confirmation of infection using other methods is often necessary to ensure the reliability of the diagnosis. According to Monaghan et al. (1994), the benefits of high sensitivity tests are greater where disease prevalence is low, but in areas where prevalence is high, a high specificity test is recommended.

A possible explanation for the presence of animals that were falsely negative for the tuberculin test $(2 / 7)$ is the

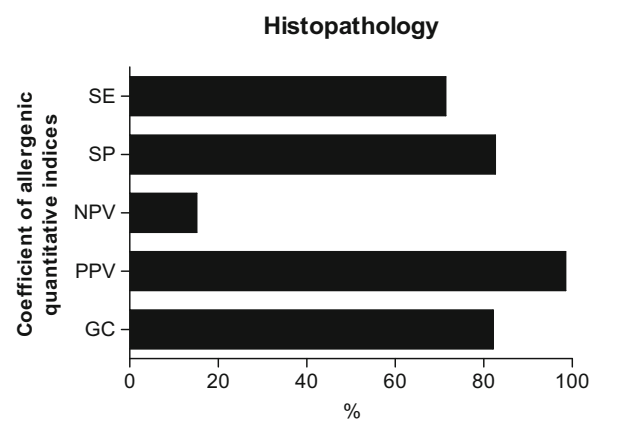

SE-Sensitivity; SP-Specificity; NPV-Negative predictive value; PPV-Positive predictive value; GC

Global coefficient

Fig. 5 The sensitivity and specificity of diagnostic tests of the allergy test with the histopathological examination results of bovine tuberculosis (Mycobacterium bovis) in buffaloes (Bubalus bubalis) from the north region of Brazil
Table 3 Qualitative analysis of the comparison between the tuberculin test and bacterial culture for tuberculosis diagnosis (Mycobacterium bovis) in buffaloes (Bubalus bubalis) from the north region of Brazil

\begin{tabular}{llll}
\hline Tuberculin test & Bacterial culture & Total \\
\cline { 2 - 3 } & Positive & Negative & \\
\hline Positive & $5(15.15 \%)(\mathrm{TP})$ & $28(84.84 \%)(\mathrm{FP})$ & 33 \\
Negative & $2(1.48 \%)(\mathrm{FN})$ & $133(98.52 \%)(\mathrm{TN})$ & 135 \\
Total & 7 & 161 & 168 \\
\hline
\end{tabular}

$T P$ true positive, $F P$ false positive, $T N$ true negative, $F N$ false negative

occurrence of a state of energy or insufficient application of PPDs due to malfunctioning of the dosing pistol. These factors were reported by Monaghan et al. (1994), who added other factors, including the use of tuberculin with low or reduced activity, animal desensitization prior to testing due to malnutrition associated with pregnancy and lactation, postpartum immunosuppression, incorrect animal identification, and variation between evaluators. The occurrence of true positive animals may have been facilitated by the animal farming system used, where animals are reared and fattened in a single physical space, which justifies the concomitant presence of positive adult females and calves in the herds studied.

The prevalence rate of $4.16 \%$ in buffaloes by histopathological examination and bacterial culture was superior to that obtained by Akhtar et al. (1992), who found a prevalence of $2.9 \%$ in buffaloes using a comparative cervical intradermal tuberculin test. Furthermore, Bonsu et al. (2000) reported that a high prevalence rate can be attributed to environmental factors, including a limited number of water sources, which encourages animal clustering, and this condition favors the transmission of bovine tuberculosis. In a study conducted in cattle in the Republic of Ireland, Costello et al. (1997) used the intradermal tuberculin test, histopathological examination, and bacterial culture as accurate diagnostic tests and observed a test sensitivity of $90.9 \%$, which was considerably higher

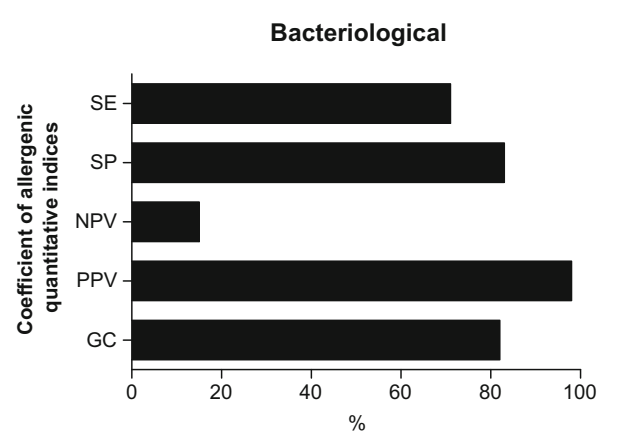

SE-Sensitivity; SP-Specificity; NPV-Negative predictive value; PPV-Positive predictive value; GCGlobal coefficient

Fig. 6 The sensitivity and specificity of diagnostic tests of the allergy test with the bacterial culture results of bovine tuberculosis (Mycobacterium bovis) in buffaloes (Bubalus bubalis) from the north region of Brazil 
than that obtained in the present study (71.43\%), suggesting an increased prevalence rate in those locations.

Barry et al. (1993) found a sensitivity of $80.2 \%$ using a simple intradermal cervical tuberculin test in cattle after confirmation by culturing, and this rate was higher than that obtained in the present study $(71.43 \%)$. These authors argue that the increased number of positive tuberculin tests and negative cultures (false positives) is due to cross-reactivity or failure in culture isolation, which can be a result of decreased viability of $M$. bovis during freezing and thawing or during sample preparation, because the reagents used prior to culture inoculation can decrease bacterial viability.

\section{Conclusions}

The comparative intradermal tuberculin test performed in buffaloes indicated a low prevalence of tuberculosis. In addition, histopathological examination and bacterial culture results indicated a high rate of false positive and true negative reactions.

The low prevalence observed using the comparative intradermal tuberculin test combined with histopathological examination and bacterial culture suggest that $M$. bovis occurred in a few animals in the animal population evaluated.

Although considered the gold standard method, bacterial culture is not recommended as a routine complementary test for the diagnosis of tuberculosis in buffaloes.

Of the animals evaluated in different mesoregions, only those farmed in the Lower Amazon were admittedly positive for M. bovis.

Acknowledgments We are grateful to Pró-Reitoria de Pesquisa e PósGraduação da Universidade Federal do Pará (PROPESP/UFPA) for typing the manuscript. This study was supported by Fundação de Amparo e Desenvolvimento da Pesquisa do Estado (FADESP). We also thank the Coordination for the Improvement of Higher Level of Education Personnel (CAPES) and National Counsel of Technological and Scientific Development $(\mathrm{CNPq})$ for the financial support.

Conflict of interest None of the authors of this work has a financial or personal relationship with other people or organizations that could inappropriately influence or bias the content of this paper.

\section{References}

Akhtar, S., Khan, M. I., Anum, A. D., 1992. Comparative delayed cutaneous hypersensitivity in buffaloes and cattle: reaction to tuberculin purified protein derivative, Buffaloes Journal, 8, 39-45.

Álvarez, J., Perez, A., Marqués, S., Bezos, J., Grau, A., Cruz, M.L., Romero, B., Saez, J.L., Esquivel, M.D.R., Martínez, M.D.C., Mínguez, O., Juan, L., Domínguez, L., 2014. Risk factors associated with negative in-vivo diagnostic results in bovine tuberculosisinfected cattle in Spain. BMC Veterinary Research, 10, 14.

Barbosa, J.D., Silva, J.B., Rangel, C.P., Fonseca, A.H., Silva, N.S., Bomjardim, H.A., Freitas, N.F.Q.R., 2014. Tuberculosis prevalence and risk factors for water buffalo in Pará, Brazil, Tropical Animal Health and Production, 46, 513-517.

Barry, T., Glennon, M., Smith, T., Gannon, F., 1993. Detection of Mycobacterium bovis in bovine blood by combined PCR and DNA probe methods, Veterinary Record, 132, 66-67.

Bonsu, O.A., Laing, A.E., Akanmori, B.D., 2000. Prevalence of tuberculosis in cattle in the Dangme-West District of Ghana, public health implications, Acta Tropica, 76, 9-14.

Cleaveland, S., Shaw, D.J., Mfinanga, S.G., Shirima, G., Kazwala, R.R., Eblate, E., Sharp, M., 2007. Mycobacterium bovis in rural Tanzania: risk factors for infection in human and cattle populations. Tuberculosis, 87, 30-43.

Costello, E., Egan, I.W.A., Quigley, F.C., O’Reilly, P.F., 1997. Performance of the single intradermal comparative tuberculin test in identifying cattle with tuberculous lesions in Irish herds, Veterinary Record, 141, 222-224.

Henken, A.M., Graat, E.A.M., Casal, J., 1997. Measurement of disease frequency. In: Noordhuizen, J.P.T.M., Frankena, K., Van Der Hoofd, C.M., Graat, E.A.M. eds. Application of quantitative methods in veterinary epidemiology. Wageningen the Netherlands: Wageningen Pers, p. 76.

Instituto Brasileiro de Geografia e Estatística - IBGE, 2013. Sistema IBGE de Recuperação de Dados (SIDRA). Instituto Brasileiro de Geografia e Estatística. http://www.ibge.com.br. Accessed 23 April 2013.

Javed, M.T., Munir, A., Shahid, M., Severi, G., Irfan, M., Aranaz, A., Cagiola, M., 2010. Percentage of reactor animals to single comparative cervical intradermal tuberculin (SCCIT) in small ruminants in Punjab Pakistan. Acta Tropica, 113, 88-91.

Láu, H.D., 1999. Doenças em búfalos no Brasil. Diagnóstico, epidemiologia e controle. Brasília: Embrapa - SPI Belém: Embrapa - CPATU, 202 p.

Mello, D., Queiroz, J.C., Galvão, T.B., 1965. Reações positivas à prova de tuberculina em búfalos, Bubalus bubalis, var. Bubalis (LINNEU 1758), Revue de Médecine Vétérinaire, 1, 115-116.

Michel, A.L., Simões, M., 2009. Comparative field evaluation of two rapid immunochromatographic tests for the diagnosis of bovine tuberculosis in African buffaloes (Syncerus caffer), Veterinary Immunology and Immunopathology, 127, 186-189.

Ministério da Agricultura, Pecuária e Abastecimento - MAPA, 2006. Programa Nacional de Controle e Erradicação da Brucelose e Tuberculose Animal (PNCEBT). Ministério da Agricultura, Pecuária e Abastecimento, Secretaria de Defesa Agropecuária, Departamento de Defesa Animal. - Brasília, 188 p.

Monaghan, M.L., Doherty, M.L., Collins, J.D., Kazda, J.F., Quinn, P.J., 1994. The tuberculin test, Veterinary Microbiology, 40, 111-124.

Mota, P.M.C., Lobato, F.C.F., Assis, R.A., Lage, A.P., Parreiras, P.M., Leite, R.C., 2002. Ocorrência de tuberculose em rebanhos bubalinos (Bubalus bubalis var. bubalis - Linneus, 1758) no município de Parintins, Amazonas, Arquivo Brasileiro de Medicina Veterinária e Zootecnia, 54, 441-443.

Phillips, C., Foster, C., Morris, P., Teverson, R., Foster, C., Morris, P., Teverson, R., 2003. The transmission of Mycobacterium bovis infection to cattle. Research in Veterinary Science, 74, 1-15.

Pinto, P.S.A., Faria, J.E., Viloria, M.I.V., Bevilacqua, P.D., 2002. Exame microbiológico da tuberculose como subsídio à inspeção postmortem de bovinos, Revista Brasileira de Saúde e Produção Animal, 3, 10-15.

Portugal, M.A.S.C., Giorg, W., Siqueira, P.A., 1971. Ocorrência de tuberculose em bubalinos (Buballus bubalis var. Bubalis lineus, 1758) no Estado de São Paulo, Arquivos do Instituto Biológico, 4, 231238.

Seva, J., Sanes, J.M., Ramis, G., Mas, A., Quereda, J.J., VillarrealRamos, B., Villar, D. and Pallares, F.J., 2014. Evaluation of the single cervical skin test and interferon gamma responses to detect Mycobacterium bovis infected cattle in a herd co-infected with 
Mycobacterium avium subsp. paratuberculosis, Veterinary Microbiology, 171, 139-146.

Tschopp, R., Schelling, E., Hattendorf, J., Aseffa, A., Zinsstag, J., 2009. Risk factors of bovine tuberculosis in cattle in rural livestock production systems of Ethiopia, Preventive Veterinary Medicine, 89, 205-211.

Wood, P.R., Corner, L.A., Rothel, J.S., Baldock, C., Jones, S.L., Cousins, D.B., McCormick, B.S., Francis, B.R., Creeper, J., Tweedlle, N.E.,
1991. Field comparison of the gamma-interferon assay and the intradermal tuberculin test for the diagnosis of bovine tuberculosis, Australian Veterinary Journal, 68, 286-290.

Zumarraga, M.J., Meikle, V., Bernardelli, A., Abdala, A., Tarabla, H., Romano, M.I., Cataldi, A., 2005. Use of touch-down polymerase chain reaction to enhance the sensitivity of Mycobacterium bovis detection. The Journal of Veterinary Diagnostic Investigation, 17, 232-238. 